\title{
Information and Announcements
}

\section{Science Academies' Refresher Course in Experimental Physics 13-28 September 2015}

\author{
Sponsored by Indian Academy of Sciences, Bangalore, \\ Indian National Science Academy, New Delhi, \\ The National Academy of Sciences, India, Allahabad \\ in collaboration with Department of Physics, Kurukshetra University, Kurukshetra
}

A Refresher Course in Experimental Physics will be held in the Department of Physics, Kurukshetra University, Kurukshetra, from September 13 to 28, 2015. This Course aims to familiarize participants with a set of experiments developed as a low cost kit by the Indian Academy of Sciences to cater to the BSc and MSc levels. All experiments verify physical laws and principles and yield reasonably accurate results.

The Course is particularly aimed at teachers teaching at UG/PG level. College/University teachers having at least a Master's degree in Physics are eligible to apply. The UGC has also approved of 2-week Refresher Courses of good standing for promotion of teachers, vide notification - F 3-1/2009 dated 30 June 2010. Motivated students of MSc/PhD Physics who have a keen interest in Experimental Physics and in teaching physics, may also apply.

Prof. R Srinivasan who designed these experiments for the benefit of physics teachers and students in Indian universities will be the Course Director. The Course comprising of lectures, discussions and laboratory sessions will help the participants hone their skills in experimental physics and enable them to introduce the experiments in their respective curricula.

Teachers/Students who wish to participate in this Refresher Course should submit their completed application form (in the prescribed format) by email or by post addressed to: Prof. R K Moudgil, Course Coordinator - Refresher Course in Experimental Physics, Department of Physics, Kurukshetra University, Kurukshetra - 136119 (Email: rkmoudgil@kuk.ac.in). The application format can be obtained from the Coordinator.

In the case of teacher applicants, a print copy of the application should be forwarded to the Course Coordinator by the Head of the Institution stating that leave will be sanctioned if the applicant is selected for the Course. Recommendation letter from a teacher is essential for student applicants. For any other query, applicants can send an Email to: rkmoudgil@kuk.ac.in or contact - 09416467846.

Last date for the receipt of application through proper channel: 22 August 2015.

Selected participants will be intimated through Email by 26 August 2015. Selected participants will be provided with local hospitality and round-trip bus/train (III AC) fare by the shortest route. 